\title{
EXPERIMENTAL MODELLING AND CONTROL OF A TOWER CRANE IN THE FREQUENCY DOMAIN
}

\author{
ČÁPKOVÁ Romana ${ }^{1}$, KOZÁKOVÁ Alena ${ }^{1}$, MINÁR Martin ${ }^{1}$ \\ ${ }^{1}$ Slovak University of Technology in Bratislava, Faculty of Electrical Engineering and Information Technology, \\ Institute of Automotive Mechatronics, Ilkovičova 3, 81219 Bratislava, Slovak Republic, \\ e-mails: romana.capkova@stuba.sk,alena.kozakova@stuba.sk,martin.minar@stuba.sk
}

\begin{abstract}
The laboratory tower crane by INTECO is used in research and education of control engineering for mechatronics. Its modelling and control include several subsystems. The paper deals with identification of dynamic model of trolley motion along the jib and trolley position controller design, as well as design of compensator to damp payload oscillations in the direction along the jib. A thorough frequency domain analysis of obtained results is provided.
\end{abstract}

KEYWORDS: Bode diagram, control, frequency domain, Nichols chart, oscillations damping, tower crane

\section{Introduction}

A crane can be described as a lifting device that lifts objects in a vertical or horizontal positions within a defined space. Cranes are often used in construction, engineering, metallurgical industries, commerce, on oil platforms, in refineries and nuclear power plants etc. Cranes can be divided into static cranes (including tower cranes, unloading cranes and telescopic cranes) and mobile cranes (including auto cranes, belt cranes, train cranes, portal cranes and ship cranes). In general, a crane construction has a supporting part, several pulleys, a jib and counterweights.

Crane control is a very difficult task and provides many problems to solve. The most important task is to ensure that the desired setpoint of the object is achieved with a required accuracy. For this reason, the control is important to minimize costs, increase work efficiency and also minimize the risk of damage to nearby objects. A serious problem are payload oscillations which can occur as a result of weather conditions or incorrect weight distribution of the carried object but primarily they are due to the payload lift-line and can be transferred to the crane construction and impair its stability. The payload oscillations can be greatly reduced using input shaping controllers in combination with PD controllers [1].

This paper deals with the above problems for a laboratory model of a tower crane (TCR) by the INTECO company who is a leader in the design and manufacture of mechatronic systems for real-time control design and implementation. The TCR laboratory plant is popular among researchers in control engineering for mechatronics. Its modelling and control include the following subsystems: motion of the trolley along the jib, angular displacement of the jib, vertical displacement of the payload, and damping of payload oscillations [2]. Specifically, the paper focuses on dynamic model identification and controller design of the trolley position along the jib, and damping of payload oscillations also along the jib. Once these problems are resolved, their solution can be generalized for angular displacement. A frequency domain analysis based on Bode and Nichols diagrams describes frequency properties of the model with the designed compensator for oscillations damping. The frequency response approach is appropriate for this kind of problems and provides good results without need of measured data 
preprocessing $[3,4]$ also in face of uncertainty in the plant model. Though there are more efficient advanced techniques for vibration damping [5], the frequency response design is often the most cost-effective design method and is most effective for open-loop stable systems.

The paper is organized into following sections: Section 2 deals with the description of the laboratory tower crane, Section 3 focuses on experimental identification of the dynamic model of the trolley motion along the jib. The trolley position controller is designed in Section 4. In Section 5, a compensator for payload oscillations damping is analysed in the frequency domain. Conclusions are drawn at the end of the paper.

\section{Laboratory Tower Crane Setup}

The tower crane in Fig. 1 by INTECO is an electromechanical three-dimensional laboratory model used for demonstration and solution of control engineering problems in mechatronics. It is delivered with a software operating in real-time under MS Windows using MATLAB and the RTW toolbox package. High-resolution sensors implemented in a unique 2D angle measuring unit enable comfortable measuring of oscillations in two directions. TCR is driven by three DC motors [2]. The length of the tower is $1.63 \mathrm{~m}$, the jib is $1.215 \mathrm{~m}$ long. A constant length $0.17 \mathrm{~m}$ of the payload lift-line is considered; the payload mass is $0.333 \mathrm{~kg}$.

Both the jib and the trolley can move of horizontal plane: the trolley can move along the jib from the "home" position up to $0.5 \mathrm{~m}$ of its length (x-direction), the jib can rotate around the vertical axis in the range $\theta \in[0, \pi]$ rad from the home position. Angular position of the jib is expressed by the angle $\theta[\mathrm{rad}]$. The operation space of the tower crane in the horizontal plane is depicted in Fig. 2. The payload attached to the end of the lift-line is lifted and lowered in the vertical direction and can move freely in three dimensions. From the viewpoint of control, TCR is a nonlinear multi input - multi output (MIMO) system controlled from a PC.

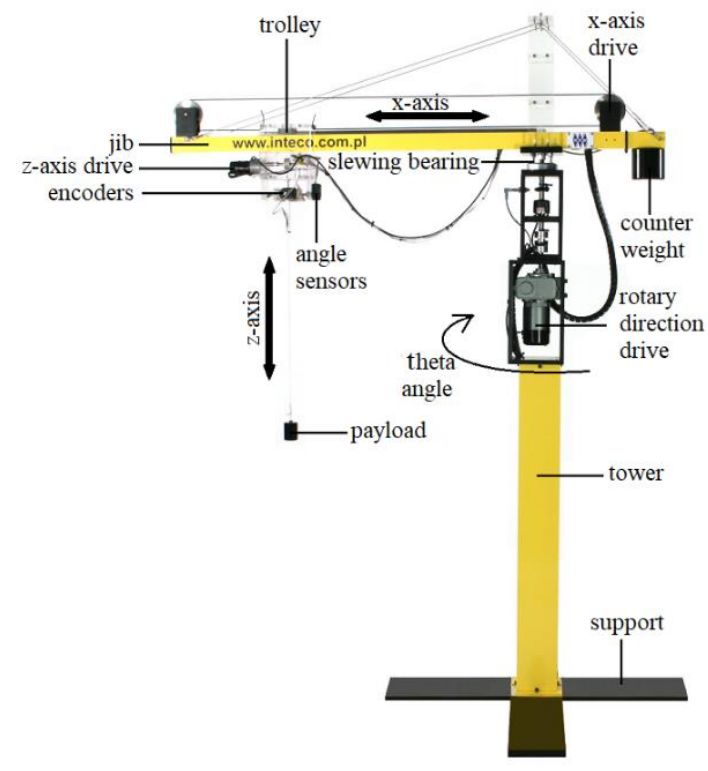

Fig. 1 TCR laboratory model setup

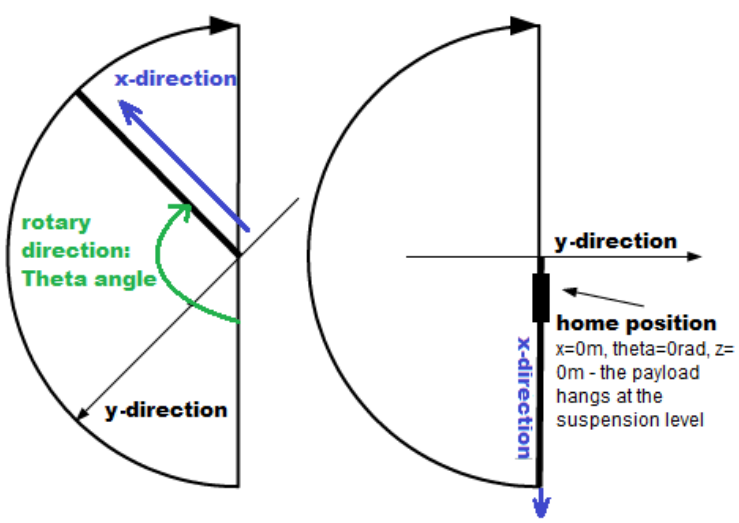

Fig. 2 Tower crane operation space 


\section{$3 \quad$ Modelling Dynamics of Trolley Motion along the Jib}

Experimental identification of the dynamics of the trolley motion along the jib (in the xdirection) was used to obtain a linear model around a working point specified from the input/output steady-state characteristics.

The input variable in [p.u.] corresponds to input voltage according to the conversion chart (linear approximation) in Fig. 3 obtained experimentally according to Table 1 . The resulting equation is $y=12.248 x-0.03$.

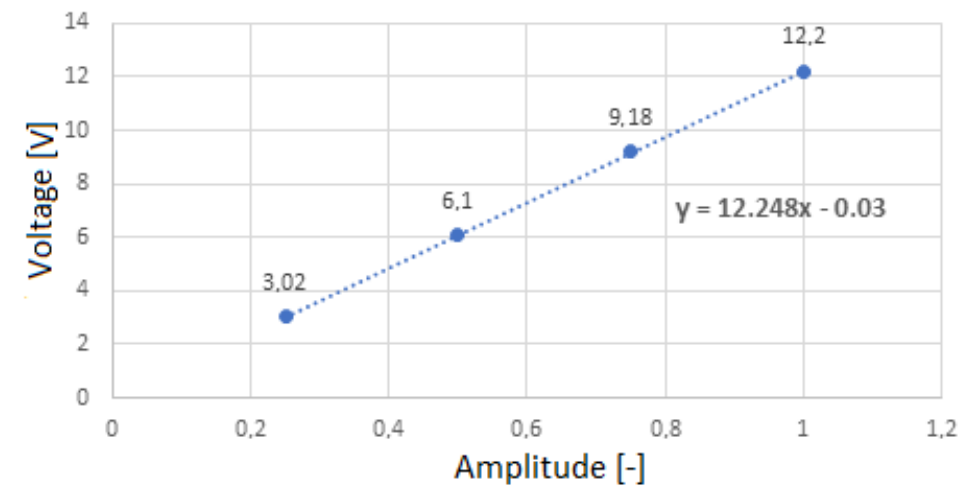

Fig. 3 Conversion of signal amplitude to voltage for the DC motor

Table 1. Values of amplitude and voltage

\begin{tabular}{|c|c|}
\hline $\begin{array}{c}\text { Amplitude } \\
\text { [p.u.] }\end{array}$ & $\begin{array}{c}\text { Voltage } \\
\text { [V] }\end{array}$ \\
\hline 0.25 & 3.02 \\
\hline 0.50 & 6.10 \\
\hline 0.75 & 9.18 \\
\hline 1.00 & 12.20 \\
\hline
\end{tabular}

The output variable is the slope of the related integrating step response (derivative of position, i.e. velocity). The resulting input/output (I/O) steady-state characteristics is depicted in Fig. 4; the working point for identification of the linear dynamic model was chosen in its linear part.

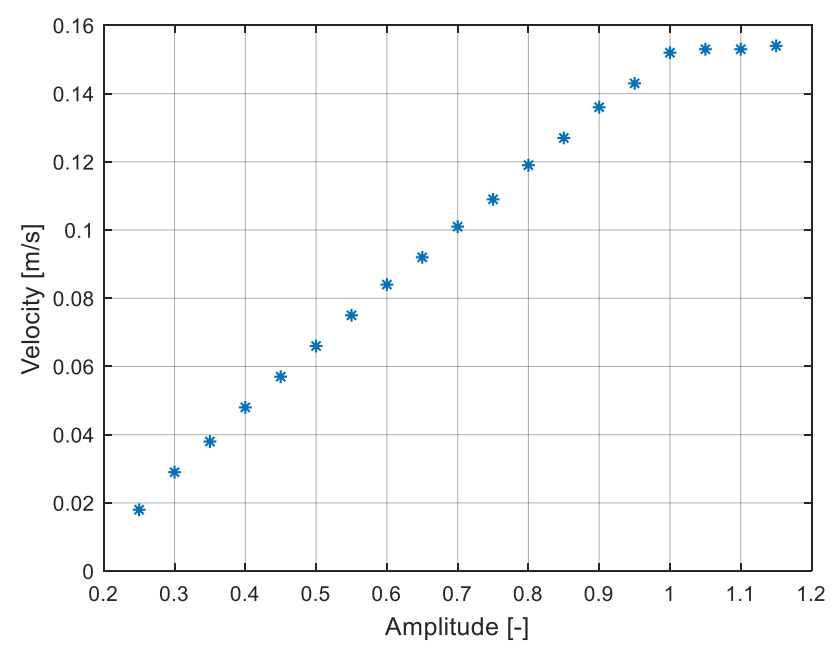

Fig. $4 \mathrm{I} / \mathrm{O}$ steady-state characteristics for the trolley motion along the jib 
The linear model of the trolley motion along the jib was identified experimentally from the integrating step response. To model the integrating process, a second order integrating transfer function was considered in the form [6]:

$$
G(s)=\frac{K}{s\left(T_{1} s+1\right)} e^{-T_{d} s}
$$

where $K$ is gain of the system, $T_{d}$ is transport delay and $T_{1}$ is time constant. $K$ is obtained from the step response of an integrating process in Fig. 5 as follows:

$$
K=\frac{\Delta h}{\Delta \mathrm{t}}
$$

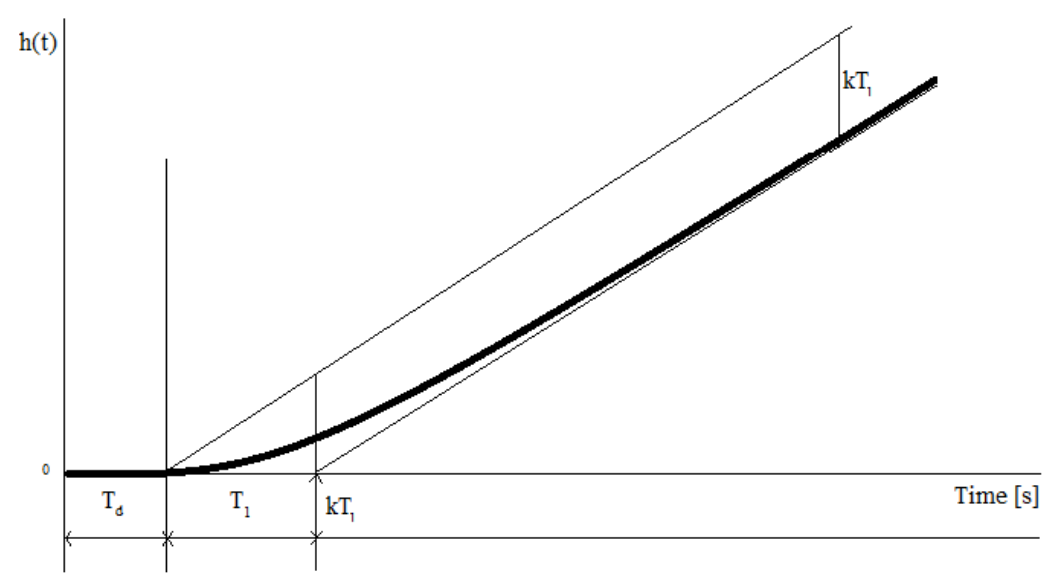

Fig. 5 Step response of an integrating process

The resulting transfer function is $\left(T_{d}=0\right)$

$$
G(s)=\frac{0.125}{s(0.01 s+1)}
$$

Quality of identification is evident from the comparison of output time responses of the real device and the model (3) in Fig. 6.

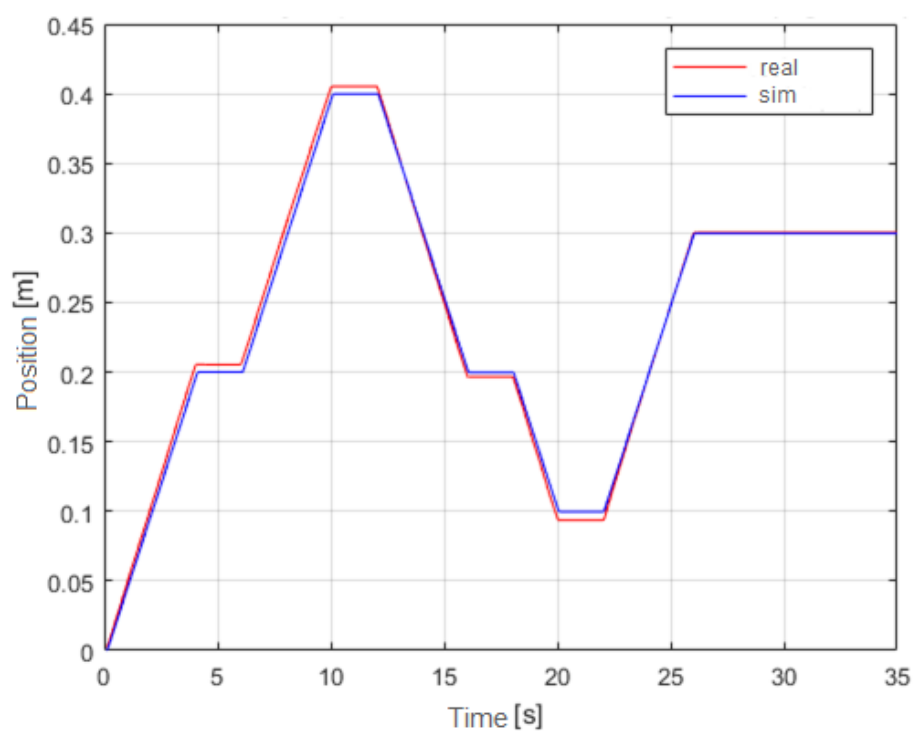

Fig. 6 Trolley position in the $\mathrm{x}$-direction 


\section{$4 \quad$ Trolley Position Controller Design}

Because the trolley motion along the jib is an integrating process, from the Final value theorem results that the appropriate PID controller structure is P or PD for a step change, and PI or PID for a ramp change of reference; next, the ramp reference is considered to avoid large control actions.

The QFT design philosophy based on Nichols chart [7,8] was used to guarantee performance specified in form of frequency-domain inequalities:

$$
\delta_{l o}(\omega)<\frac{G(j \omega) G_{R}(j \omega)}{1+G(j \omega) G_{R}(j \omega)} \leq \delta_{u p}(\omega)
$$

where $\delta_{l o}(\omega), \delta_{u p}(\omega)$ are lower and upper performance bounds, respectively, obtained in form of transfer functions (5) and (6).

$$
\begin{gathered}
\delta_{l o}(s)=\frac{\left(1-\varepsilon_{l o}\right)}{\left(\frac{s}{a_{L}}+1\right)^{2}} ; 0 \leq \varepsilon_{l o} \\
\delta_{u p}(s)=\frac{\left[\left(\frac{s}{a_{U}}\right)+1\right]\left(1+\varepsilon_{u p}\right)}{\left[\left(\frac{s}{\omega_{n}}\right)^{2}+\left(\frac{2 \xi s}{\omega_{n}}\right)+1\right]} ; 0 \leq \varepsilon_{u p} ; \xi=0.8 ; \omega_{n}=\frac{1.25 a_{U}}{\xi}
\end{gathered}
$$

Following recommended parameter values [8] were used to calculate the lower bound: $a_{L}=1, \varepsilon_{l o}=0.01$. For the upper bound, following parameters were found: $a_{U}=2, \varepsilon_{u p}=$ 0.025 .

The proposed bounds delineate the allowable area for the step response (Fig. 7, red and blue plots).

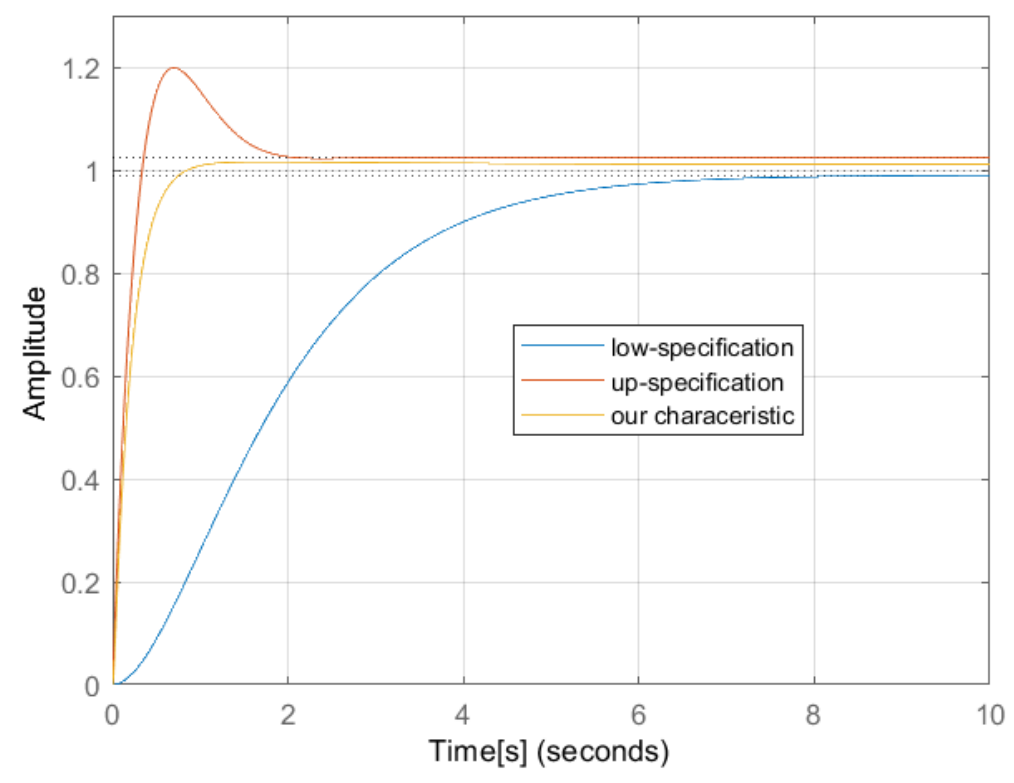

Fig. 7 Closed-loop step response with bounds 
Open-loop Bode plots (controlled system under the designed controller) along with the upper and lower bounds are depicted in Fig. 8.

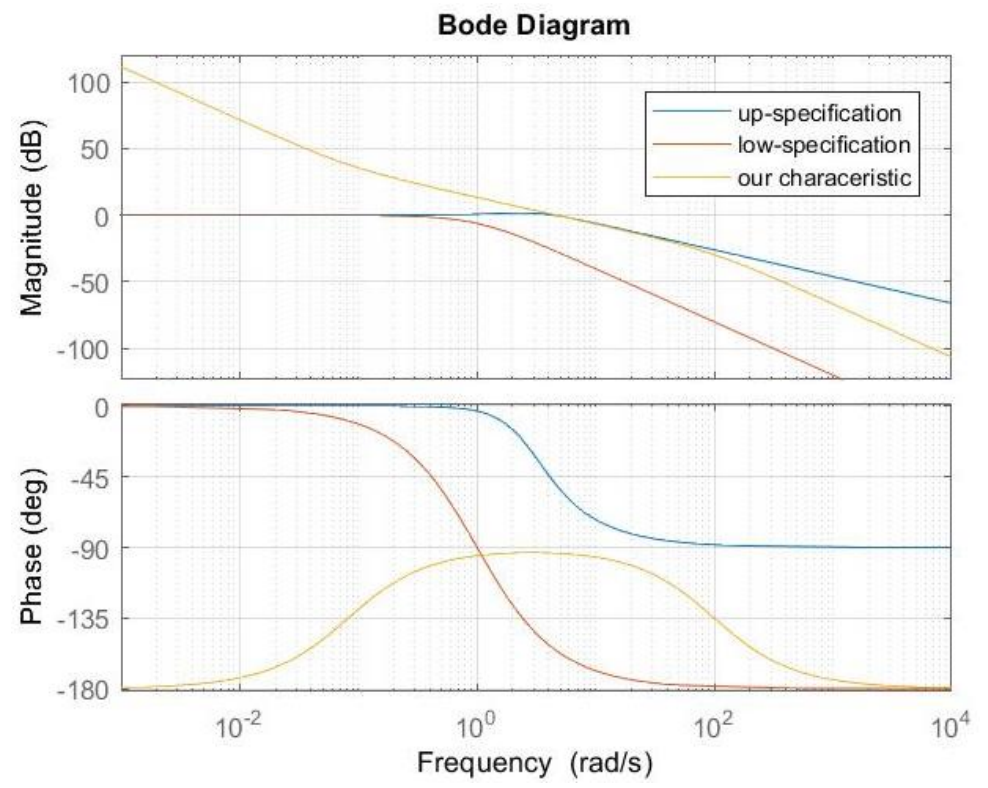

Fig. 8 Bode diagram with performance specifications

A PI controller was tuned experimentally using the pidTuner tool in Matlab and has the following transfer function:

$$
G_{R}(s)=\frac{37.4649 s+3.068}{s}
$$

A sufficiently large stability margin $(86.3 \mathrm{deg}$ ) is evident from the Bode diagram in Fig. 8 (the yellow plot is the compensated open-loop, red and blue plots are the lower and upper bounds, respectively). Closed-loop responses obtained via simulation and real experiments are compared in Fig. 9.

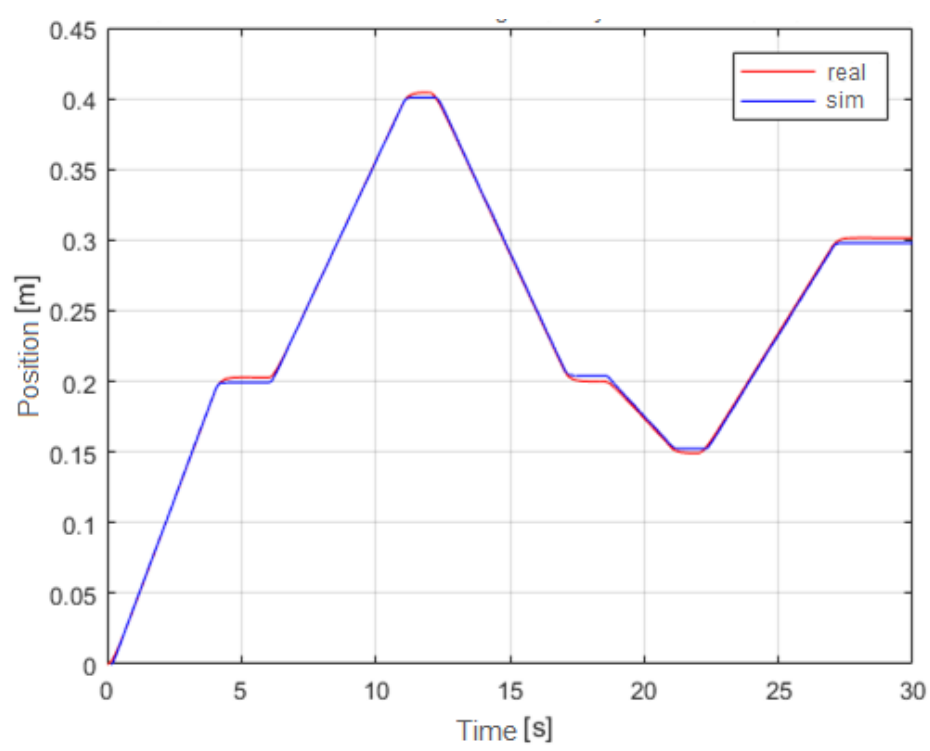

Fig. 9 Closed-loop response of trolley position

Implementation of the PI controller in the TCR simulation scheme in Matlab-Simulink for the real experiment is shown in Fig. 10. 


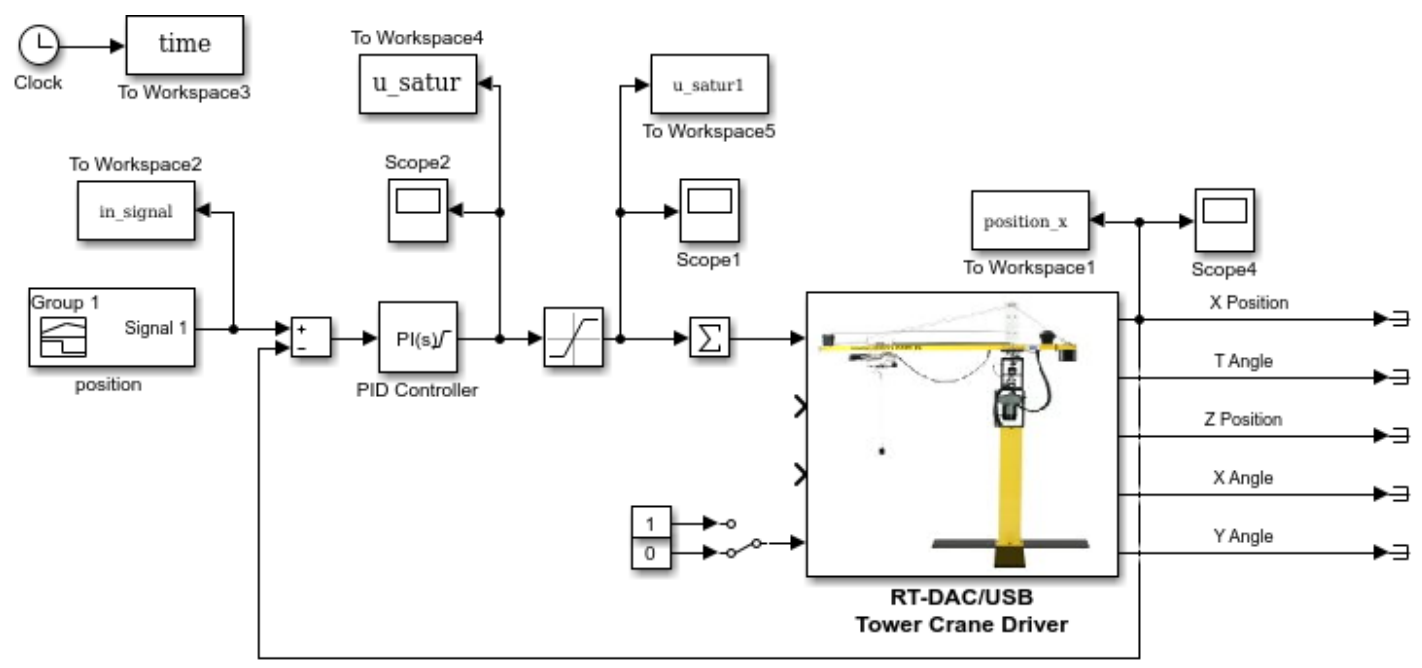

Fig. 10 Block scheme with the PI controller for real-time experiments

\section{Payload Oscillations Damping Using a Compensator}

When the trolley moves and mainly when it stops in the required position, oscillations of the payload arise; they present an undesirable and dangerous disturbance in payload position control.

Oscillation dynamics was identified from the oscillating response to a step change at the input to the trolley motion subsystem (with the position control loop closed). Dynamic model of payload oscillations was identified from the step response using the systemIdentification tool in Matlab. From various model types of second and third orders (Fig. 11 and Fig. 12) the $3^{\text {rd }}$ order oscillatory transfer function was selected:

$$
\begin{aligned}
G(s) & =\frac{0.1354}{0.000763 s^{3}+0.01638 s^{2}+0.04889 s+1}= \\
& =\frac{0.1354}{(0.0469 s+1)\left(0.0163 s^{2}+0.00203 s+1\right)}
\end{aligned}
$$

A very small relative damping $(b \approx 0.008)$ in the transfer function $(8)$ is evident from the time response in Fig. 11, and from Bode plots obtained from measured data in Fig. 12.

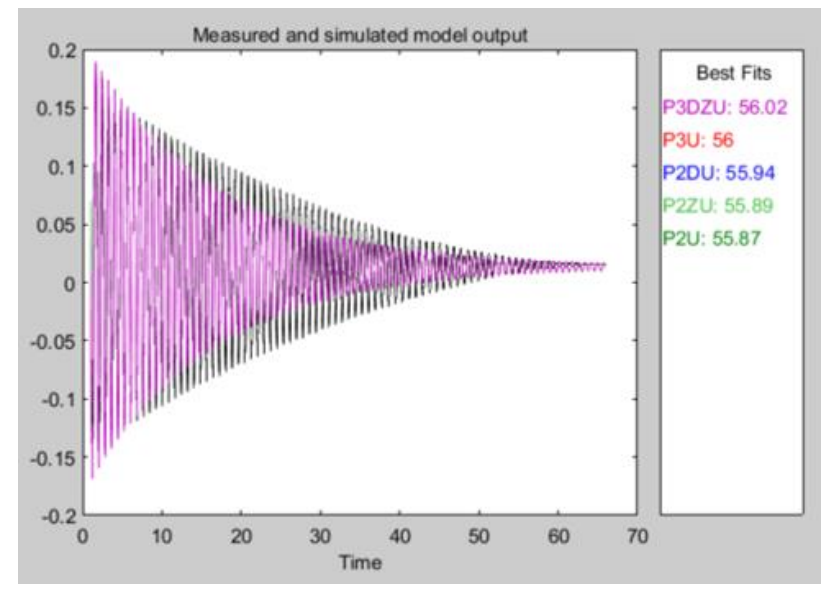

Fig. 11 Measured and simulated model outputs

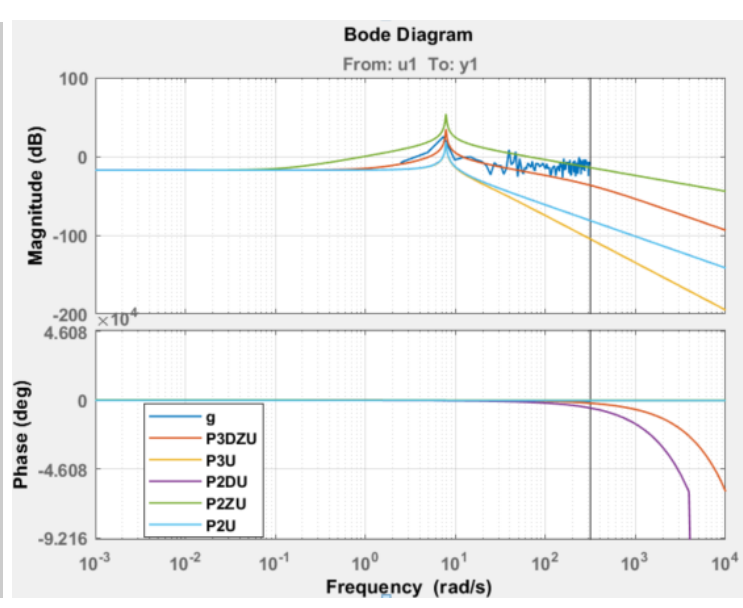

Fig. 12 Bode diagrams from measured data and their approximations 
The plots in Fig. 11 (time responses) and Fig. 12 (frequency responses) correspond to the following identified transfer functions (standard Matlab notation is used):

$2^{\text {nd }}$ order: P2U - underdamped with 2 poles, P2ZU - underdamped with 2 poles 1 zero and P2DU - underdamped with 2 poles with transport delay

$3^{\text {rd }}$ order: P3U - underdamped with 3 poles and P3DZU - underdamped with 3 poles 1 zero with transport delay.

A PID compensator was designed experimentally to increase the damping, i.e. to reasonably decrease the resonance peak of the open-loop frequency response [4]:

$$
G_{r}(s)=\frac{0.05 s^{2}+5 s+50}{s}
$$

To verify the designed compensator, the payload was manually moved aside from the steady state position (in $t_{1}=9 \mathrm{~s}, t_{2}=19 \mathrm{~s}$ and $t_{3}=26 \mathrm{~s}$ ); arisen oscillations were damped quickly as it is obvious from Fig. 13. A considerable reduction of the resonance peak of the compensated subsystem is shown in Fig. 14. A considerable difference in damping is obvious by comparing Fig. 11 (underdamped oscillations) and Fig. 13 (damped oscillations using the PID compensator).

The complete simulation scheme is depicted in Fig. 15.

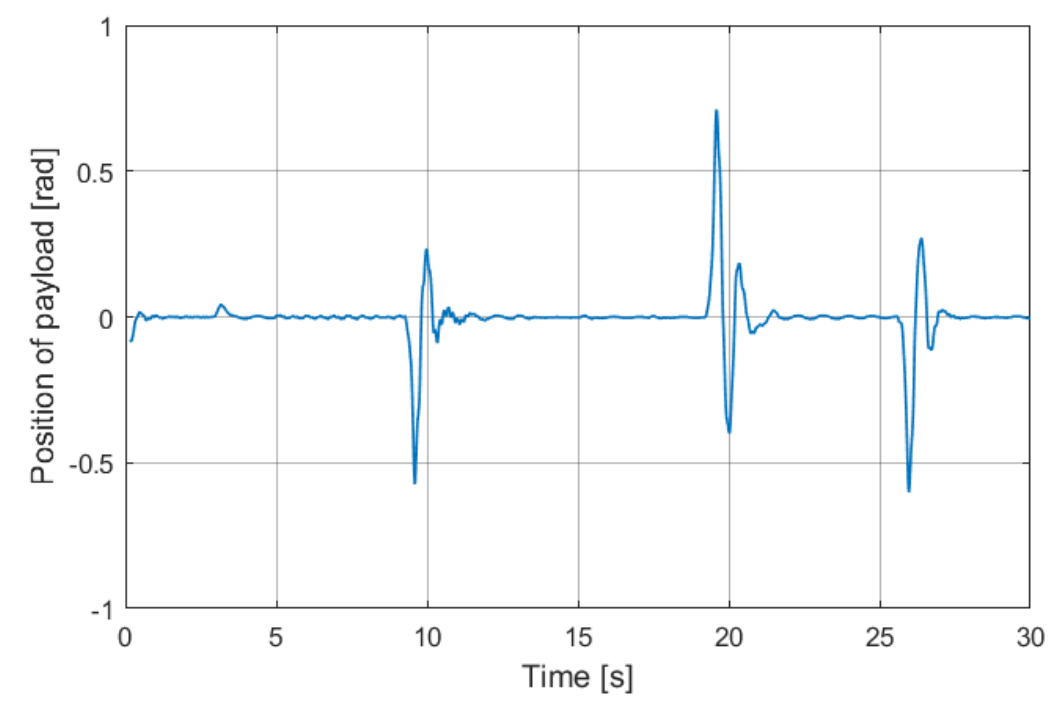

Fig. 13 Time response of damped payload oscillations 


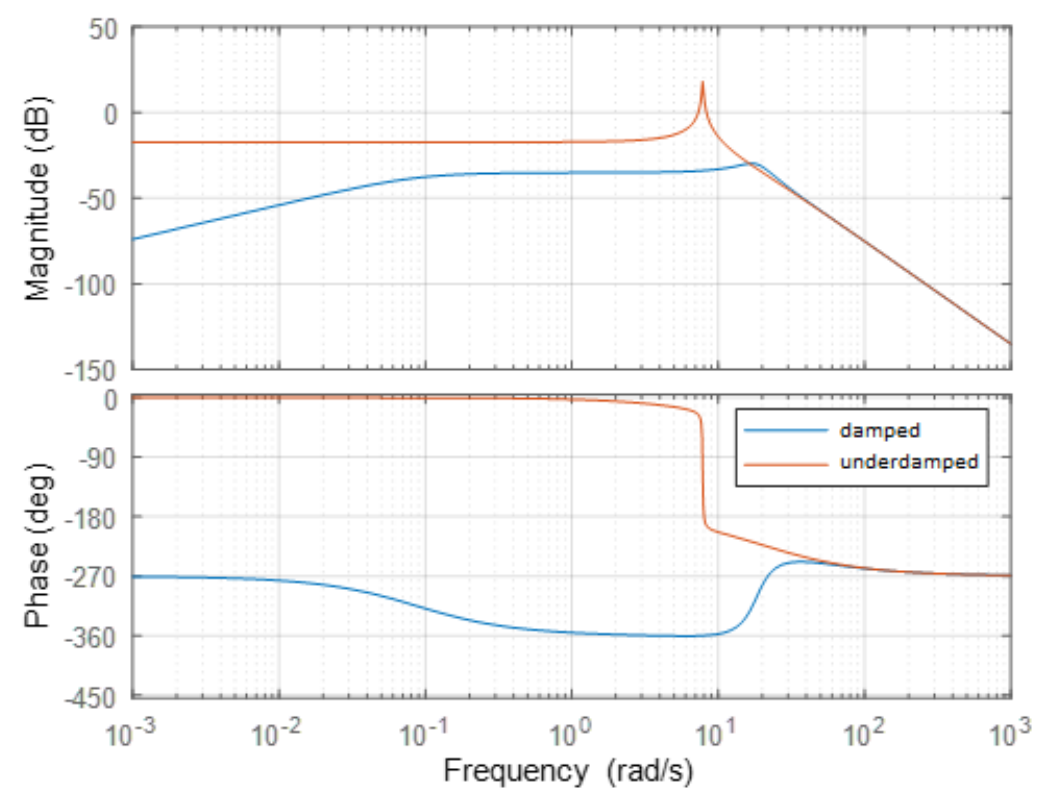

Fig. 14 Bode diagram of the payload oscillations subsystem with the designed compensator

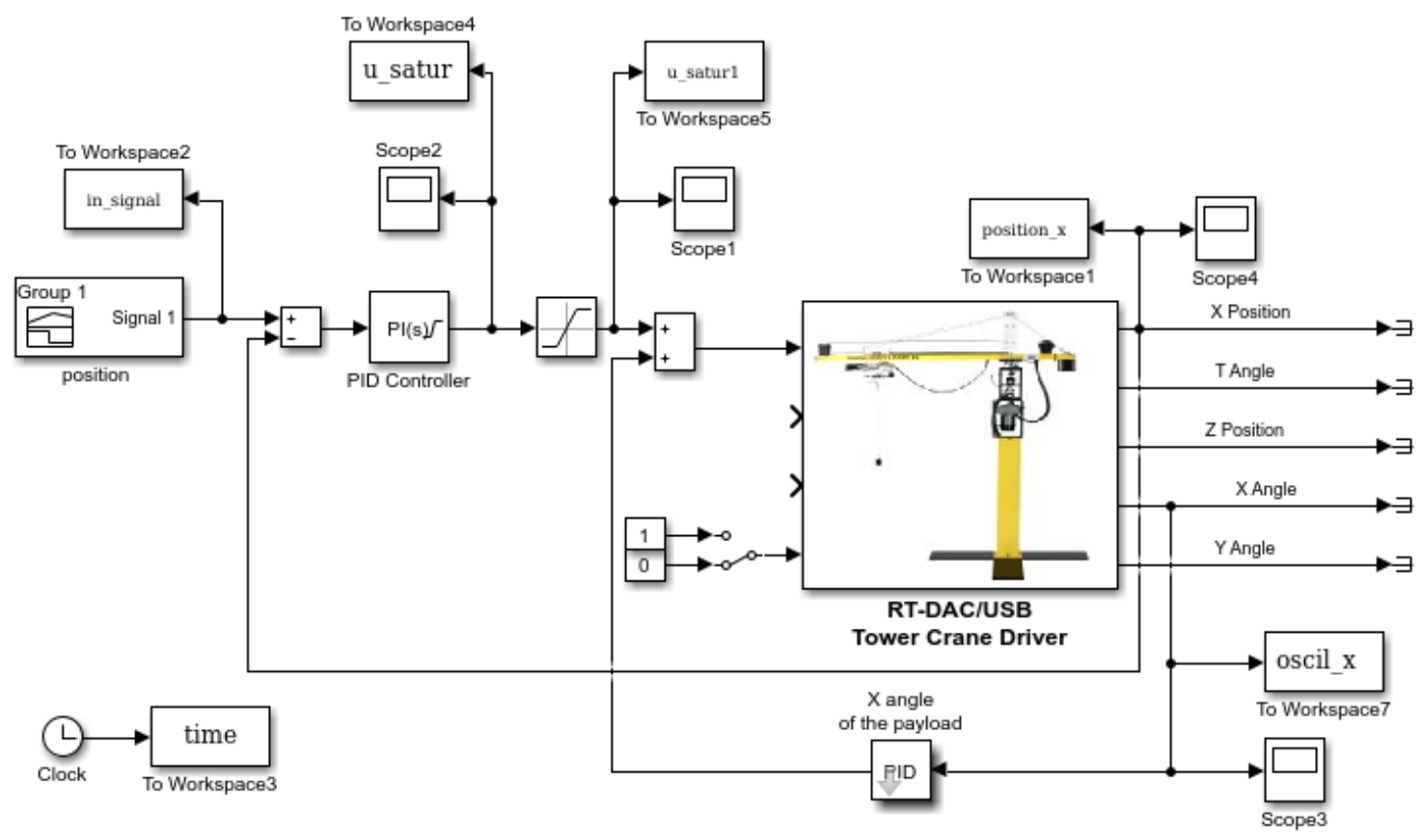

Fig. 15 Simulation scheme with the trolley position controller and oscillation damping compensator

\section{CONCLUSION}

In the paper, controller design for the laboratory tower crane was presented. For the trolley motion along the jib and related arisen oscillations, a PI controller and a PID compensator were designed, respectively. In both cases, closed-loop performance was analysed in the frequency domain using Bode diagrams. Design of a controller for oscillations damping is a very specific and non-trivial problem that can be best solved in the frequency domain. The future research will focus on damping of oscillations in both (x-y) directions, evoked by both the trolley motion along the jib, and the rotation of the jib for various lengths of the payload lift-line. 


\section{ACKNOWLEDGEMENTS}

This work was supported by the Slovak Research and Development Agency, grant APVV17-0190, and the Slovak Scientific Grant Agency, grant No. 1/0819/17.

\section{REFERENCES}

[1] Singhose W. et al. "Applications and educational uses of crane oscillation control", FME Transactions 34, pp. $175-183,2006$.

[2] Tower Crane - User's manual. ver. 9.6, INTECO, Ltd., [online] Available at: https://alab.ee/man/Towercrane-user-manual.pdf [Accessed: 7.2.2013]

[3] Úradníček J., Musil M., Bachratý M. "Frequency response function measurement on simplified disc brake model", Strojnícky časopis - Journal of Mechanical Engineering 68 (3), pp. 225 - 230, 2018. DOI: 10.2478/scjme-2018-0036

[4] Minár, M., Čápková R., Kozáková A., Goga V. "Experimental modelling and control of a tower crane using Nichols chart" In: Applied mechanics, Ostrava, Czech Republic, 2019, pp. 135 - 140. ISBN 978-80-248-4287-5

[5] Benrahmoune M., Hafaifa A., Guemana M., Chen X. "Detection and Modeling Vibrational Behavior of a Gas Turbine Based on Dynamic Neural Networks Approach", Strojnícky časopis - Journal of Mechanical Engineering 68 (3), 143 - 166, 2018. DOI: 10.2478/scjme-2018-0032

[6] Šulc B., Vítečková M. “Teorie a praxe návrhu regulačních obvodů”, Vydavatelství ČVUT, Praha, 2004. ISBN 80-01-03007-5

[7] Chen W., Ballance D. J. "Stability Analysis on the Nichols Chart and its Application in QFT", Glasgow, August 1997. [online] Available at: citeseerx.ist.psu.edu/viewdoc/summary?doi=10.1.1.35.1879

[8] Garcia-Sanz V. M. "Robust Control Engineering: Practical QFT Solutions", Boca Raton: CRC Press, Taylor \& Francis Group, 2017. ISBN 978-1-138-03207-1 